\title{
Sympathoadrenal, Metabolic, and Regional Blood Flow Responses to Cold in Fetal Sheep
}

\author{
FRANK VAN BEL, CHRISTINE ROMAN, HARRIET S. IWAMOTO, AND ABRAHAM M. RUDOLPH \\ Cardiovascular Research Institute and Departments of Pediatrics, Obstetrics, Gynecology, and Reproductive \\ Sciences, University of California, San Francisco, California 94143-0544
}

\begin{abstract}
Because environmental temperature falls when the fetus is delivered from the uterus, the role of cold in stimulating cardiovascular and sympathoadrenal responses at the time of birth was examined in fetal lambs. In eight fetuses (gestational age $140 \pm 2 \mathrm{~d}$ ), catheters were inserted into hind-limb and neck arteries and veins, and into an umbilical vein. After returning the fetus to the uterus and administering a muscle relaxant (succinylcholine chloride), blood gases, glucose and lactate concentrations, and plasma catecholamine and atrial natriuretic peptide concentrations were measured. Fetal combined ventricular output and organ blood flows were measured by the radionuclide-labeled microsphere technique. Measurements were repeated after delivering the fetus into a warm water bath $\left(40^{\circ} \mathrm{C}\right)$ and at 15 and $30 \mathrm{~min}$ after the bath temperature was cooled to $25^{\circ} \mathrm{C}$. Fetal cooling stimulated a sympathoadrenal response, which was manifested by an immediate increase in heart rate and arterial blood pressure, a rise in atrial natriuretic peptide, and a modest increase in norepinephrine concentration. Contrary to earlier reports that investigated the effect of cold on fetal lambs using an intrauterine cooling coil, we did not find a decrease in fetal arterial oxygen tensions and $\mathrm{pH}$, an increase in plasma glucose and lactate concentrations, or changes in fetal oxygen consumption. Combined ventricular output did not increase with cooling, and blood flow to most organs did not change significantly; however, blood flow to the skin decreased markedly, particularly in the lower body. The dramatic increases in catecholamine concentrations often noted after birth do not appear to be related to surface cooling; it is suggested that hypoxemia and acidemia occurring at the time of delivery could be responsible. (Pediatr Res 34: 47-50, 1993)
\end{abstract}

\section{Abbreviations}

ANP, atrial natriuretic peptide

Birth is a complex process involving rapid adjustments in many organ systems. Previously, we have reported that rhythmic expansion of the lungs, oxygenation, and placental separation result in some of the hemodynamic changes occurring normally after birth $(1,2)$ but did not produce the large increase in cardiac output that occurs in newborn lambs after delivery $(3,4)$. We entertained the possibility that the usual rise in cardiac output after birth was associated with perinatal sympathoadrenal stimulation, because it is well known that plasma catecholamine

Received November 6, 1992; accepted February 24, 1993.

Correspondence and reprint requests: Abraham M. Rudolph, M.D., Box 0544. HSE 1403, University of California, San Francisco, San Francisco, CA 94143-0544. Supported by PHS Grant HL 35842. concentrations are very high in newborn animals and infants $(5$, 6). In our study, as well as in the study of Smith et al. (7), catecholamine concentrations did not increase with ventilation, oxygenation, and umbilical-cord clamping in utero. However, fetal temperature was not changed in these studies. Because of the dramatic fall in environmental temperature when the fetus is delivered from the uterus into the atmosphere, we considered the possible role of cold in producing sympathoadrenal stimulation and increasing cardiac output in fetal lambs.

In the present study, fetal lambs were instrumented in utero, delivered into a warm-water bath while maintaining the umbilical-placental circulation, and then subjected to surface cooling. Fetal cardiovascular variables and regional blood flow, $\mathrm{pH}$, and blood gases, plasma catecholamine, atrial natriuretic peptide, blood glucose and lactate concentrations, and oxygen consumption were measured during these events. We also measured ANP concentrations because we hypothesized that surface cooling might produce peripheral vasoconstriction and divert blood volume into the central circulation, with a resulting increase in atrial blood volume.

\section{MATERIALS AND METHODS}

Animals and surgical preparation. Before the initiation of these studies, all surgical and experimental procedures were approved by the Committee on Animal Research at the University of California, San Francisco. We studied eight fetal sheep at 135 to $143 \mathrm{~d}$ gestational age (mean $\pm 1 \mathrm{SD}: 140 \pm 2 \mathrm{~d}$ ). The ewe was fasted for at least $24 \mathrm{~h}$ before surgery. After local anesthesia with $2 \%$ lidocaine, low epidural anesthesia was achieved with $4 \mathrm{~mL}$ of $1 \%$ tetracaine hydrochloride (Pontocaine $\mathrm{HCl}$; Breon Laboratories, New York, NY). Polyvinyl catheters were advanced into the ewe's descending aorta and inferior vena cava. $\mathrm{NaCl} 0.9 \%$ solution was infused continuously into the ewe, and 50 to 100 mg of ketamine hydrochloride (Ketalar; Parke-Davis, Morris Plains, NJ) was administered to the ewe as necessary to maintain sedation.

Through a midline incision in the ewe's abdomen, the pregnant horn of the uterus was exposed, and a uterine incision was made overlying the fetal hind limbs. Local anesthetic $(0.25 \%$ lidocaine hydrochloride) was administered before each fetal skin incision. Polyvinyl catheters were placed in the fetal descending aorta and inferior vena cava via the hind-limb vessels. The fetal skin and uterine incisions were sutured. A cotyledonary vein was identified, and a catheter was inserted and advanced toward the fetus so that the tip was positioned in one of the main umbilical veins. A second uterine incision was made overlying the fetal neck, and polyvinyl catheters were inserted into the carotid artery and external jugular vein.

Experimental procedure. Fetal arterial blood pressure and heart rate were monitored continuously throughout the experimental period, using Statham P23Db strain-gauge transducers and Beckman R612 (Beckman Instruments, Inc., Palo Alto, CA) or Gould 2800S (Gould, Inc., Cleveland, $\mathrm{OH}$ ) polygraphs. Heart 
rate was recorded with a cardiotachometer triggered by the arterial pressure pulse. Blood samples were obtained from the descending aorta for determination of $\mathrm{pH}, \mathrm{PO}_{2}, \mathrm{PCO}_{2}$ (corrected to actual fetal temperature), blood oxygen saturation, and $\mathrm{Hb}$ concentration (model 158 Blood Gas Analyzer, Corning Medical, Medfield, MA; model OSM2 Hemoximeter, Radiometer, Copenhagen, Denmark) and for determination of glucose and lactate concentrations (models no. 23A and 23L glucose and lactate analyzers, Yellow Springs Instrument Co., Yellow Springs, $\mathrm{OH}$ ). Blood samples were also collected for assay of norepinephrine and epinephrine concentrations by HPLC and electrochemical detection (ESA model 5700, ESA Inc., Bedford, MA). The technique has been reported previously (8). Blood was also collected for measurement of ANP concentrations by RIA, as described in detail previously (9). Combined ventricular output and blood flow distribution of the fetus were determined by injecting four differently labeled $15-\mu \mathrm{m}$ microspheres (selected from ${ }^{75} \mathrm{Co},{ }^{51} \mathrm{Cr}$, ${ }^{153} \mathrm{Gd},{ }^{114} \mathrm{In},{ }^{54} \mathrm{Mn},{ }^{95} \mathrm{Nb},{ }^{113} \mathrm{Sn},{ }^{85} \mathrm{Sr}$, or ${ }^{65} \mathrm{Zn}$; New England Nuclear, Boston, MA) into the inferior vena cava while obtaining reference samples at a rate of $4 \mathrm{~mL} / \mathrm{min}$ from the descending aortic and carotid arterial catheters. The volume of blood removed for analyses and for flow reference samples was replaced with an equal volume of fetal donor blood, or, in a minority of cases, with maternal blood.

Before obtaining any measurements, we injected succinylcholine chloride, a muscle relaxant, into the fetal vein in a dose of $10 \mathrm{mg}$. This dose was repeated every 15 to $20 \mathrm{~min}$ throughout the procedure to avoid fetal movement or shivering when exposed to cold. The fetus was first studied in utero and then after delivery into a water bath. Special care was taken to avoid tension or pressure on the umbilical cord during the exteriorization procedure. Blood samples were collected and flow measurements performed during four conditions: 1 ) with the fetus in utero (control condition), 2) $15 \mathrm{~min}$ after submersion of the whole fetus in a water bath at $39^{\circ} \mathrm{C}$ (warm bath condition), 3) after 15 min in a water bath of $25^{\circ} \mathrm{C}$ (cold bath condition), 4) after 30 min (core-cooling condition) after the water-bath temperature was lowered to $25^{\circ} \mathrm{C}$, and 5) $30 \mathrm{~min}$ after rewarming the water bath to $40^{\circ} \mathrm{C}$ (rewarm condition). Blood flow was not measured during the rewarm condition.

Upon completion of the last set of measurements, the ewes were killed with an i.v. injection of $10 \mathrm{~g}$ of sodium pentobarbital (Euthanasia-6; Veterinary Laboratories, Lexena, KS). Combined ventricular output and its distribution were determined as described previously in detail (10). Briefly, the uterus, individual fetal organs, skin, and carcass (bone and muscles) were dissected, weighed, placed in formalin, carbonized in an oven at $350^{\circ} \mathrm{C}$, and ground into a coarse powder. The ash of the different tissues was then placed in plastic vials to a uniform height of $3 \mathrm{~cm}$ and counted in a 1000-channel multichannel pulse-height analyzer (Norland Corp., Fort Atkinson, WI). The activity of each isotope in each organ and tissue was determined by the least-squares method, as described previously (10). Blood flow to fetal organs, skin, and carcass was calculated in each condition by comparing the radioactivity of the microspheres in each organ or tissue with the radioactivity and flow rate of the appropriate reference sample (brachiocephalic trunk for upper body organs and tissue, descending aorta for lower body organs and tissue), as described previously in detail (11).

Statistical analysis. All data are summarized as mean \pm 1 SD. Differences between mean values during the different conditions were assessed by one-factor analysis of variance in case of a normal distribution of the variables, followed by the NewmanKeuls test when a significant difference was found. The KruskalWallis one-way analysis of variance was used to analyze differences between plasma norepinephrine, epinephrine, and ANP concentrations, because these variables did not have a normal distribution, followed by the Wilcoxon rank-sum test when a significant difference was found. A $p$ value $<0.05$ was considered statistically significant.

\section{RESULTS}

The values for fetal rectal temperature, arterial $\mathrm{pH}, \mathrm{PO}_{2}, \mathrm{PCO}_{2}$, arterial oxygen saturation and oxygen consumption, and arterial glucose and lactate concentrations during the different conditions are summarized in Table 1. All variables were stable, and no significant differences were found between the study periods except in fetal rectal temperature, which was significantly lower after $30 \mathrm{~min}$ in the cold water and after rewarming as compared with the in utero condition. The $\mathrm{PO}_{2}$ and oxygen saturation were within the range considered normal for fetal lambs in utero, but $\mathrm{PCO}_{2}$ values were slightly higher and $\mathrm{pH}$ values slightly lower than those of chronically instrumented fetal lambs. Arterial glucose and lactate concentrations were stable throughout the study and within normal limits for fetal lambs in utero. Fetal blood $\mathrm{Hb}$ concentration was stable throughout the study period.

Table 2 summarizes the hemodynamic data during the various conditions. Immediately after submersion in cold water $\left(25^{\circ} \mathrm{C}\right)$, fetal heart rate and arterial blood pressure showed a steep increase. Heart rate and mean arterial blood pressure were significantly higher at 15 and $30 \mathrm{~min}$ after the start of cooling compared with the in utero and the warm bath conditions. During the rewarming condition, heart rate and blood pressure returned to values similar to those found in the warm bath. Combined ventricular outputs and umbilical-placental blood flows were somewhat lower than those reported previously for chronically instrumented fetal lambs. However, combined ventricular output, as well as placental blood flow, did not change significantly when the fetus was delivered into the warm bath, nor did it change during cooling.

Plasma norepinephrine and epinephrine concentrations did not change significantly when the fetus was delivered into the warm bath. Norepinephrine concentrations increased in each of the eight animals when the bath water was cooled, but epinephrine concentrations did not change significantly. ANP concentrations were significantly increased in the cold bath and returned to baseline values after rewarming (Fig. 1).

Table 3 summarizes the blood flows to various organs and tissues. Although, in most organs and body tissues, blood flows decreased somewhat with core cooling, this difference was not significant. However, with core body temperature reduction, there was a significant decrease of blood flow to the lower carcass and skin. In one lamb in which it was measured, brown-fat blood flow increased significantly after cold exposure as compared with in utero and warm bath conditions. Total fetal vascular resistance increased after cooling, but this reached significance only after core cooling had occurred (Table 2).

\section{DISCUSSION}

Exposure of the adult and newborn animal to cold stimulates the sympathoadrenal system, with an increase in heart rate, blood pressure, and cardiac output, redistribution of blood flows, a rise in catecholamine (particularly blood norepinephrine) concentrations, and an increase in oxygen consumption $(12,13)$. We found that the fetal response is similar; heart rate and blood pressure increase, and norepinephrine concentrations rise. However, combined ventricular output did not increase, only a limited response of cardiac output distribution resulted, and fetal oxygen consumption did not increase.

The response to cooling has been studied in utero in fetal lambs in which a plastic coil was placed around the chest or inserted into the abdomen, and cooling was induced by circulating cold water through the coil (14-16). Our preparation was different in several respects. The fetus was exteriorized so that the whole body could be cooled, the ewe was sedated with ketamine administered i.v., and the fetus was given succinylcholine to produce muscle paralysis. The latter was done to assess the effect of cooling without shivering. Ketamine produces only minor and transient hemodynamic effects in the doses we used $(17,18)$. Fetal arterial $\mathrm{PO}_{2}$ was within the normal range for fetal 
Table 1. Blood gases, pH, oxygen saturation, and glucose and lactate concentrations of fetal descending aortic blood, and fetal oxygen consumption during various conditions

\begin{tabular}{|c|c|c|c|c|c|}
\hline & In utero & Warm bath & Cold bath & Core cooling & Rewarm \\
\hline Fetal rectal temperature $\left({ }^{\circ} \mathrm{C}\right)$ & $38 \pm 0.61$ & $38.17 \pm 0.55$ & $37.11 \pm 1.04$ & $35.06 \pm 2.51^{*}$ & $36.95 \pm 0.61^{*}$ \\
\hline $\mathrm{pH}$ & $7.25 \pm 0.04$ & $7.26 \pm 0.04$ & $7.27 \pm 0.04$ & $7.29 \pm 0.02$ & $7.26 \pm 0.04$ \\
\hline $\mathrm{PCO}_{2}(\mathrm{kPa})$ & $8.9 \pm 1.1$ & $9.0 \pm 1.1$ & $8.6 \pm 0.9$ & $7.7 \pm 0.9$ & $8.8 \pm 0.8$ \\
\hline $\mathrm{PO}_{2}(\mathrm{kPa})$ & $3.3 \pm 0.8$ & $3.1 \pm 0.5$ & $3.1 \pm 0.9$ & $2.8 \pm 0.4$ & $2.7 \pm 0.4$ \\
\hline $\mathrm{O}_{2}$ saturation $(\%)$ & $56 \pm 13$ & $53 \pm 10$ & $54 \pm 14$ & $56 \pm 10$ & $48 \pm 8$ \\
\hline $\mathrm{O}_{2}$ consumption $(\mathrm{mL} / \mathrm{kg} / \mathrm{min})$ & $5.84 \pm 0.53$ & $5.83 \pm 2.46$ & $4.84 \pm 1.52$ & $4.76 \pm 1.29$ & \\
\hline Glucose (mmol/L) & $1.2 \pm 0.5$ & $1.1 \pm 0.4$ & $1.2 \pm 0.4$ & $1.4 \pm 0.4$ & $1.0 \pm 0.4$ \\
\hline Lactate $(\mathrm{mmol} / \mathrm{L})$ & $1.8 \pm 0.3$ & $1.8 \pm 0.6$ & $1.6 \pm 0.4$ & $1.7 \pm 0.5$ & $2.1 \pm 0.3$ \\
\hline
\end{tabular}

$* p<0.01$ vs in utero.

Table 2. Hemodynamic data of fetuses during various conditions

\begin{tabular}{|c|c|c|c|c|c|}
\hline & In utero & Warm bath & Cold bath & Core cooling & Rewarm \\
\hline Heart rate (beats/min) & $175 \pm 34$ & $174 \pm 26$ & $242 \pm 29 * \dagger$ & $229 \pm 17^{*} \dagger$ & $200 \pm 53$ \\
\hline Mean aortic pressure $(\mathrm{mm} \mathrm{Hg})$ & $64 \pm 5$ & $63 \pm 9$ & $75 \pm 5^{*}+$ & $73 \pm 7^{*} \dagger$ & $66 \pm 17$ \\
\hline Placental flow $(\mathrm{mL} / \mathrm{kg} / \mathrm{min})$ & $127 \pm 33$ & $115 \pm 36$ & $131 \pm 45$ & $87 \pm 54$ & $\mathrm{NM} \ddagger$ \\
\hline Combined ventricular output $(\mathrm{mL} / \mathrm{min} / \mathrm{kg})$ & $342 \pm 77$ & $416 \pm 120$ & $419 \pm 86$ & $344 \pm 121$ & NM \\
\hline Total vascular resistance $\left(\mathrm{mm} \mathrm{Hg} \cdot \mathrm{mL}^{-1} \cdot \mathrm{kg}^{-1} \cdot \mathrm{min}^{-1}\right)$ & $0.19 \pm 0.05$ & $0.16 \pm 0.05$ & $0.19 \pm 0.04$ & $0.25 \pm 0.1 \dagger$ & NM \\
\hline
\end{tabular}

$p<0.05 v s$ intrauterine.

$\dagger p<0.05$ vs. warm bath.

$\ddagger N M$, not measured.

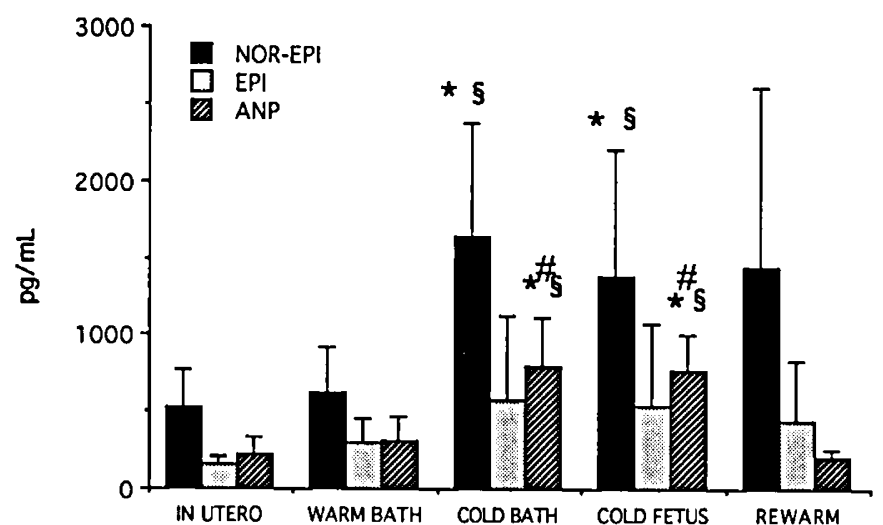

Fig. 1. Fetal plasma norepinephrine (NOR-EPI), epinephrine (EPI), and ANP concentrations during the various conditions. ${ }^{*}, p<0.05$ vs intrauterine condition; $\S, p<0.05$ vs warm bath condition; \#, $p<0.05$ vs rewarm condition.

Table 3. Fetal regional blood flow $(\mathrm{mL} / 100 \mathrm{~g} / \mathrm{min}$ ) responses during various conditions

\begin{tabular}{lcccc}
\hline & In utero & Warm bath & Cold bath & Core cooling \\
\hline Brain & $129 \pm 66$ & $171 \pm 63$ & $217 \pm 79$ & $154 \pm 87$ \\
Heart & $133 \pm 35$ & $168 \pm 66$ & $233 \pm 62$ & $198 \pm 84$ \\
Adrenals & $287 \pm 150$ & $428 \pm 251$ & $337 \pm 131$ & $195 \pm 94$ \\
Kidneys & $140 \pm 32$ & $157 \pm 41$ & $134 \pm 59$ & $103 \pm 20$ \\
Liver* & $10 \pm 10$ & $22 \pm 21$ & $14 \pm 14$ & $16 \pm 13$ \\
Spleen & $261 \pm 115$ & $321 \pm 113$ & $234 \pm 114$ & $138 \pm 107$ \\
Intestines & $59 \pm 19$ & $62 \pm 32$ & $47 \pm 26$ & $39 \pm 14$ \\
Upper carcass & $16 \pm 6$ & $20 \pm 6$ & $18 \pm 5$ & $15 \pm 7$ \\
Upper skin & $11 \pm 5$ & $13 \pm 3$ & $11 \pm 7$ & $8 \pm 7$ \\
Lower carcass & $12 \pm 3$ & $17 \pm 8$ & $14 \pm 7$ & $9 \pm 4 \dagger$ \\
Lower skin & $12 \pm 6$ & $12 \pm 3$ & $7 \pm 2 \dagger \ddagger$ & $4 \pm 2 \dagger \ddagger$ \\
\hline
\end{tabular}

* Represents only hepatic arterial blood flow.

$\dagger p<0.05$ vs warm bath.

$\ddagger p<0.05 v s$ intrauterine.

lambs chronically instrumented in utero, but $\mathrm{PCO}_{2}$ was slightly higher and $\mathrm{pH}$ slightly lower than normal. This was the result of mild respiratory depression in the ewe, associated with some carbon dioxide retention. This mild acidemia did not affect baseline catecholamine concentrations, which were in the same range as those reported in chronically instrumented fetal lambs in utero $(19,20)$. Baseline ANP concentrations were also in the range found in fetal lambs in utero. However, in contrast with several other reported studies in which a similar preparation was used (14-16), metabolic acidosis did not develop in our fetal lambs. Furthermore, umbilical-placental blood flow, cardiac output, and organ blood flow showed no significant changes, and neither did $\mathrm{pH}$ or blood gases.

The increases in heart rate and blood pressure with cooling were similar to those reported with cooling in utero (14-16) and could be the result of sympathoadrenal stimulation, as manifested by the rise in norepinephrine concentrations. Norepinephrine concentrations increased almost 3-fold in our study with cooling, but they did not reach the very high concentrations frequently noted in newborn animals or infants after birth. The birth events of ventilation, oxygenation, and umbilical cord occlusion, when performed on fetal lambs in utero, had only minor effects on catecholamine concentrations $(1,7)$. Padbury et al. (21) found that exteriorization of fetal sheep resulted in a small increase in catecholamine concentrations, but concentrations rose markedly after occluding the umbilical cord. However, cord occlusion was associated with severe hypoxemia, acidemia, and hypercarbia in many of these lambs. Hypoxemia and acidemia are potent stimuli for catecholamine production in fetal lambs $(22,23)$. Sack et al. (24) studied the effects of cooling on FFA concentrations in lambs but did not measure catecholamine concentrations. FFA probably represent the effects of sympathoadrenal stimulation. They noted that fetal cooling produced only small increases in FFA concentrations, but cutting the umbilical cord produced a large increase in FFA. Unfortunately, they did not report specific $\mathrm{PO}_{2}, \mathrm{PCO}_{2}$, or $\mathrm{pH}$ changes associated with cutting the umbilical cord in this group of animals. It is not possible to exclude the potential contribution of hypoxia or acidemia to the observed response.

Gunn et al. $(14,15)$, using a model in which the fetal lamb was cooled in utero, found that plasma catecholamine concentrations increased with cooling but rose dramatically after umbilical cord occlusion. In one of these studies, the fetuses became quite hypoxic and acidemic after cord compression. In the second study, they ventilated the fetuses with a high-oxygen gas mixture before occluding the cord. Although fetal arterial $\mathrm{PO}_{2}$ was maintained, $\mathrm{PCO}_{2}$ increased, and because hypercarbia stimulates release of catecholamines (25), it is difficult to separate the effects of cord occlusion alone from those of hypoxemia or hypercarbia. 
Certainly, occlusion of the cord in the well-ventilated fetus in utero has only a minor influence on catecholamine concentrations (1, 7). Also, Habib et al. (26) found that, after birth of term fetal lambs, plasma concentrations of catecholamines increased only modestly to concentrations comparable to those observed in this study with fetal cooling. Although a combination of cooling and cord occlusion may be responsible for the very high catecholamine concentrations at birth, we are of the opinion that modest or severe hypoxemia, hypercarbia, and acidemia, often accompanying natural delivery, are likely the predominant causes of the marked rise in catecholamine concentrations at birth. The increase in ANP concentrations after fetal cooling could well be due to an increase in central blood volume resulting in atrial stretching, induced by peripheral vasoconstriction as indicated by the decrease in skin blood flow (Table 3) and increase in peripheral vascular resistance (Table 3).

Cooling did not result in any change in fetal oxygen consumption in our studies. Gunn et al. (14) observed fetal hypoxemia when they cooled lamb fetuses in utero and suggested this could be related to an increase in fetal oxygen consumption to maintain body temperature. The difference in our findings possibly can be explained by the fact that we used a muscle relaxant, succinylcholine chloride, because we wished to prevent shivering and thus observe the effects of cold on metabolic stimulation alone. Shivering causes a marked increase in oxygen consumption of the newborn lamb exposed to cold, and muscle relaxation dramatically reduces this response (13). Although shivering was reported in fetal lambs cooled in utero (27), using a similar model, Kawamura et al. (16) found no change in blood flow to the carcass. Had shivering been important in affecting oxygen consumption, a considerable increase in muscle blood flow would have been anticipated. They did, however, observe an increase in brown-fat blood flow, as did we, suggesting that there is some increase in nonshivering thermogenesis, but not of a degree sufficient to increase oxygen consumption significantly. The issue of the relative roles of shivering and brown-fat metabolism in energy metabolism at the time of birth requires further exploration.

Furthermore, cooling did not result in any change of combined ventricular output, even though there was a modest increase in norepinephrine concentrations. It is thus apparent that neither cooling alone, nor the combined influence of ventilation, oxygenation, and cord occlusion (14) causes the expected postnatal increase in cardiac output. Some combination of cooling with the other events could account for the changes in cardiac output, or, possibly, the increase in cardiac output is related to other factors. In addition to the lack of change in combined ventricular output, cooling had no effect on organ blood flows, apart from a reduction in skin blood flow, particularly in the lower portion of the body. This reduction in skin flow could be related to vasoconstriction resulting from direct local effects of cold or to the increase in circulating norepinephrine concentrations. This peripheral vasoconstriction was probably responsible for the increase in arterial pressure associated with cooling. Calculated fetal total vascular resistance increased after cooling, but this increase was significant after fetal core body temperature fell.

The increase in ANP concentrations associated with surface cooling could be related to peripheral vasoconstriction, particularly of veins, resulting in an increase in central blood volume with atrial distention. We did not measure left or right atrial pressure, but blood volume redistribution is a likely cause for the change.

In summary, this study shows that exteriorization of the nearterm lamb fetus into a warm bath does not change hemodynamic, metabolic, or hormonal parameters as compared with the fetus in utero. Surface cooling causes tachycardia and hypertension but no changes in cardiac output or organ blood flows, apart from a reduction in skin flow. Although catecholamine concentrations increase with surface cooling, they did not reach the high levels often reported after birth, and we conclude that marked elevations of catecholamine concentrations are probably related to associated hypoxemia and respiratory or metabolic acidemia.

\section{REFERENCES}

1. Iwamoto HS, Teitel D, Rudolph AM 1987 Effect of birth-related events on blood flow distribution. Pediatr Res 22:634-640

2. Teitel D, Iwamoto HS, Rudolph AM 1987 Effects of birth-related events on central blood flow patterns. Pediatr Res 22:557-566

3. Klopfenstein HS, Rudolph AM 1978 Postnatal changes in the circulation, and responses to volume loading in sheep. Circ Res 42:839-845

4. Lister G, Walter TK, Versmold HT, Dallman PR, Rudolph AM 1979 Oxygen delivery in lambs: cardiovascular and hematologic development. Am J Physiol 237:H668-H675

5. Lagercrantz H, Bistoletti $P 1973$ Catecholamine release in the newborn infant at birth. Pediatr Res 11:889-893

6. Slotkin TA, Seidler FJ 1988 Adrenomedullary catecholamine release in the fetus and newborn: secretory mechanisms and their role in stress and survival. J Dev Physiol 10:1-16

7. Smith FG, Smith BA, Segar JL, Robillard JE 1991 Endocrine effects of ventilation, oxygenation and cord occlusion in near-term fetal sheep. $J$ Dev Physiol 15:133-138

8. Iwamoto HS, Kaufman T, Keil LC, Rudolph AM 1989 Responses to acute hypoxemia in fetal sheep at 0.6-0.7 gestation. Am J Physiol 256:H613H620

9. Hargrave BY, Iwamoto HS, Rudolph AM 1989 Renal and cardiovascular effects of atrial natriuretic peptide in fetal sheep. Pediatr Res 26:1-5

10. Baer RW, Payne BA, Verrier ED, Vlahakes GJ, Molodowitch D, Uhlig PN, Hoffman JIE 1984 Increased number of myocardial blood flow measurements with radionuclide-labeled microspheres. Am J Physiol 246:H418$\mathrm{H} 434$

11. Heymann MA, Payne BD, Hoffman JIE, Rudolph AM 1977 Blood flow measurements with radionuclide-labeled particles. Prog Cardiovasc Dis 20:55-79

12. Alexander G, Bell AW 1982 The role of the adrenal gland in the metabolic response of young lambs to cold. J Dev Physiol 4:53-73

13. Alexander G, Williams D 1968 Shivering and non-shivering thermogenesis during summit metabolism in young lambs. J Physiol (Lond) 198:251-276

14. Gunn TR, Johnston BM, Iwamoto HS, Fraser M, Nicholls MG, Gluckman PD 1985 Haemodynamic and catecholamine responses to hypothermia in the fetal sheep in utero. J Dev Physiol 7:241-249

15. Gunn TR, Butler J, Gluckman PD 1986 Metabolic and hormonal responses to cooling the fetal sheep in utero. J Dev Physiol 8:55-66

16. Kawamura T, Gilbert RD, Power GG 1986 Effect of cooling and heating on the regional distribution of blood flow in fetal sheep. J Dev Physiol 8:11-21

17. Trevor AJ, Miller RD 1987 General anesthetics. In: Katzung BG (ed) Basic and Clinical Pharmacology. Appleton and Lange, Los Altos, CA, pp 279288

18. Appel E, Dudziak R, Palm D, Wnuk A 1979 Sympathoneuronal and sympathoadrenal activation during ketamine anesthesia. Eur J Pharmacol 16:9195

19. Cheung CY, Brace RA 1987 Norepinephrine regulation of fetal heart rate: multiple mechanisms of action. Am J Obstet Gynecol 156:1254-1259

20. Davidson $D 1987$ Circulating vasoactive substances and hemodynamic adjustments at birth in lambs. J Appl Physiol 63:676-684

21. Padbury JF, Diakomanolis ES, Hobel CJ, Perelman A, Fisher DA 1981 Neonatal adaptation: sympatho-adrenal response to umbilical cord cutting. Pediatr Res 15:1483-1487

22. Cohen WR, Piasecki GJ, Jackson BT 1982 Plasma catecholamines during hypoxemia in fetal lamb. Am J Physiol 243:R520-R525

23. Lewis A, Evans WN, Sischo W 1982 Plasma catecholamine responses to hypoxemia in fetal lambs. Biol Neonate 41:115-122

24. Sack J, Beaudry M, DeLamater PV, Oh W, Fisher DA 1976 Umbilical cord cutting triggers hypertriiodothyroninemia and nonshivering thermogenesis in the newborn lamb. Pediatr Res 10:169-175

25. Faucher DJ, Laptook AR, Porter JC, Rosenfeld CR 1991 Effects of acute hypercapnia on maternal and fetal vasopressin and catecholamine release. Pediatr Res 30:368-374

26. Habib DM, Padbury JF, Martinez AM, Chappell BA. Thio SL, Burnell EE 1991 Neonatal adaptation: cardiac adrenergic effector mechanisms after birth in newborn sheep. Pediatr Res 29:98-103

27. Gluckman PD, Gunn TR, Johnston BM 1983 The effect of cooling on breathing and shivering in unanaesthetized fetal lambs in utero. J Physiol (Lond) 343:495-506 